\title{
Influência dos Níveis das Correntes, Ângulo de Inclinação da Tocha e Distância entre a Tocha e a Peça sobre a Geometria do Cordão de Solda Usando "Plasma-MIG" com Arcos Concêntricos
}

\author{
André Alves de Resende ${ }^{1}$, Américo Scotti \\ 1 Curso de Engenharia de Produção, Universidade Federal de Goiás - UFG, Catalão, GO, Brasil. \\ 2 Universidade Federal de Uberlândia - UFU, Laprosolda, Uberlândia, MG, Brasil.
}

Recebido: 11 Jul., 2015

Aceito: 22 Dez., 2015

E-mails: aaresende@gmail.com (AAR), ascotti@ufu.br(AS)
Resumo: Um adequado controle da poça fundida é de fundamental importância para obtenção de soldas em conformidade geométrica com as especificações de projeto. O processo "Plasma-MIG" com Arcos Concêntricos tem sido apresentado como uma alternativa inovadora neste sentido. Desta forma, este trabalho objetivou ampliar os estudos relacionados ao balanço das correntes entre o eletrodo consumível e o arco externo, ao ângulo de inclinação da tocha e à distância entre a tocha e a peça sobre a performance do processo. Soldagens de simples deposição sobre chapa foram executadas na posição plana, visando identificar individualmente o efeito de cada das variáveis sobre a geometria do cordão. A corrente no arco externo foi avaliada em quatro níveis e os efeitos dos demais parâmetros foram avaliados em três níveis. Foi observado que incrementos na corrente do arco externo favorece o aumento da largura, penetração e área fundida e redução do reforço. O aumento da distância da tocha até a peça fez o reforço aumentar e as larguras, penetração e área fundida diminuíram. Quanto ao ângulo de ataque da tocha, a largura e área fundida aumentaram e o reforço e penetração diminuíram quando se muda do modo puxando para empurrando.

Palavras-chave: "Plasma-MIG"; Geometria do cordão de solda; Arcos concêntricos; Parâmetros de soldagem.

\section{Influence of the Current Level, Torch Angle and Distance to the Plate on the Weld Bead Geometry Using "Plasma-MIG" with Concentric Arcs}

\begin{abstract}
An appropriate control of the welding pool is essential for obtaining welds in conformity with design specifications. The "Plasma-MIG" with concentric arcs process has appeared as an innovative option in this direction. Thus, this work aimed to expand the studies related to the influence of the balance of current between the consumable electrode and the external arc, to the torch angle and to torch-plate distance on the process performance. Bead on plate welds were carried out aiming to identify individually the effect of each of the variables on the bead geometry. The extern arc current was evaluated at four levels and the effect of the remaining parameters was evaluated at three levels. Increases of extern arc current promotes wider beads, deeper penetration, larger molten area and lower reinforcement. When the distance electrode-plate was lengthened, the reinforcement increased and the width, penetration and melt area decreased. Concerning the torch angle, the width and melt area increased and the reinforcement and penetration decreased when the position changes from pulling to pushing.
\end{abstract}

Key-words: "Plasma-MIG"; Weld bead geometry; Concentric arcs; Welding parameters.

\section{Introdução}

O processo de soldagem "Plasma-MIG" com arcos concêntricos é uma evolução do processo MIG/MAG convencional, ao qual foi adicionado um segundo arco concêntrico ao arco do metal consumível. Apesar de ser referenciado em artigos especializados e patentes como processo de soldagem "Plasma-MIG", esse nome não é o mais adequado, uma vez que o arco externo não tem todas as características do processo de soldagem Plasma. Na configuração de tocha utilizada neste trabalho, para permitir a passagem concomitante do arco externo e do arame-eletrodo, o eletrodo plasma e seu bocal não fazem o efeito de constrição do arco (tal como no processo de soldagem a Plasma), mas apenas o direciona. Desta forma, o nome ideal para o processo de soldagem seria MIG/MAG com Dois Arcos
Este é um artigo publicado em acesso aberto (Open Access)
sob a licença Creative Commons Attribution Non-Commerc que permite uso, distribuicão e reprodução em qualquer meio, sem restriçōes desde que sem fins comerciais e que 0 trabalho original seja corretamente citado. 
Concêntricos. Mas mesmo assim, por tradição, se manterá neste trabalho a denominação “Plasma-MIG", sempre "entre aspas" para chamar a atenção do leitor.

A Figura 1a mostra de forma esquemática uma tocha de soldagem do processo, destacando os principais componentes. É observada a existência de duas fontes de soldagem, uma MIG/MAG, responsável pelo arco interno (eletrodo consumível), e uma Plasma, responsável pelo arco externo (eletrodo não consumível). O eletrodo não consumível é feito de cobre, com formato anular, o que permite a passagem de forma concêntrica do eletrodo consumível. Ainda é observado o fornecimento de três gases para o processo (gás interno, gás intermediário e gás externo). Oliveira [1] e Resende [2] denominam os gases interno, intermediário e externo respectivamente por gases MIG, plasma e de proteção, no entanto, esta última denominação não é coerente uma vez que associa o gás ao respectivo arco e na região de formação dos arcos interno e externo existe a participação de no mínimo dois gases na composição da mistura responsável pelo arco. As distâncias de posicionamento dos principais elementos da tocha estão apresentadas no esquema da Figura 1b. Os valores de RA (recuo do eletrodo anular) e RM (recuo do bico de contato MIG) são fixos e dependem da característica de construção da tocha. Já os valores de DTP (distância da tocha à peça) e, consequentemente, DBCP (distância bico de contato à peça) e distância do eletrodo anular a peça (RA + DTP) podem ser variados. A abertura do arco externo é realizada com o auxílio de um arco MIG/MAG de baixa potência num procedimento denominado "soft start". Neste procedimento, o arco MIG/MAG (arco interno) é aberto com uma corrente baixa (em torno de $30 \mathrm{~A}$ ) e é recuado em direção ao eletrodo anular. Quando ocorre a aproximação do arco interno ao eletrodo anular, o arco externo também é iniciado (maiores detalhes podem ser obtidos em [1,2]).

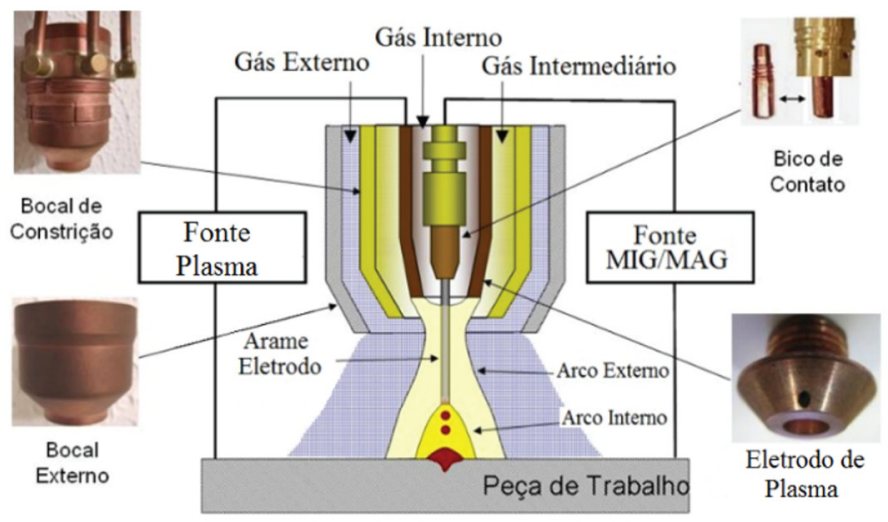

(a)

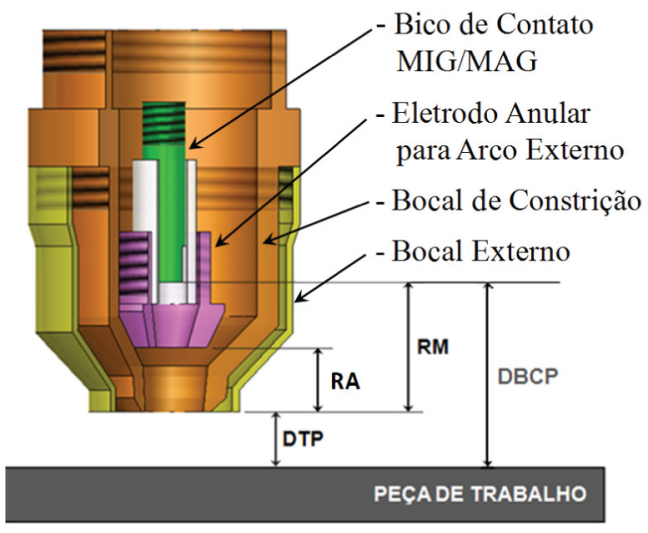

(b)

Figura 1. (a) Desenho esquemático de uma tocha para soldagem "Plasma-MIG" com Arcos Concêntricos, com destaque para os componentes principais (adaptado de Oliveira [1]); (b) Vista esquemática do posicionamento dos principais elementos da tocha, onde DTP é a distância da tocha à peça, RA o recuo do eletrodo anular e RM o recuo do bico de contato MIG.

No processo MIG/MAG e em outros processos baseados em eletrodos consumíveis, a taxa de alimentação do metal de adição está estreitamente interligada com a corrente de soldagem e com o comprimento do eletrodo. Este fato traduz a forte dependência existente entre o aporte de energia e o aporte de material dos processos que trabalham com eletrodos consumíveis. Para Oliveira [1], uma das principais consequências desta dependência é a dificuldade em se atuar na geometria do cordão de solda. Harris [3] aponta que o controle independente do arco externo e da corrente que flui através do eletrodo consumível permite, por outro lado, um melhor controle sobre o metal depositado, melhorando a produtividade e dando maior flexibilidade no controle do calor que é transferido à peça. 
Influência dos Níveis das Correntes, Ângulo de Inclinação da Tocha e Distância entre a Tocha e a Peça sobre a Geometria do Cordão de Solda Usando "Plasma-MIG" com Arcos Concêntricos

De acordo com Essers et al. [4], além da corrente que passa pelo arame, deve ser considerada no comportamento do processo "Plasma-MIG" com arcos concêntricos a corrente responsável pela ionização da atmosfera que envolve o arco do arame-eletrodo (arco externo). Essers [5], soldando com um modelo de tocha similar ao utilizados neste trabalho e usando arame-eletrodo de aço carbono, mostrou que incrementos de $300 \mathrm{~A}$ de corrente no arco externo aumentava em apenas $1 \mathrm{~mm}$ a penetração do cordão de solda. Mas, por outro lado, o efeito sobre a largura do cordão foi bastante pronunciado, fazendo a mesma variar entre 14 e $27 \mathrm{~mm}$ para uma corrente no eletrodo de $215 \mathrm{~A}$, comprimento de eletrodo energizado de $40 \mathrm{~mm}$ e velocidade de soldagem de $0,35 \mathrm{~mm} / \mathrm{s}$. Oliveira [1], soldando com o mesmo modelo de tocha utilizado neste trabalho e também usando arame-eletrodo de aço carbono, avaliou a largura do cordão em função da corrente (pulsada) no arco externo. Mesmo variando a corrente média do arco interno em cada ensaio para que a taxa de deposição do arame permanecesse constante, foram conseguidas variações na largura do cordão entre 4 e $9 \mathrm{~mm}$ para correntes no arco externo de 50 a $200 \mathrm{~A}$, respectivamente. Liu et al. [6], também pulsando a corrente no arco interno e variando seu valor médio para manter constante a velocidade de alimentação do arame, observaram durante a soldagem de juntas sobrepostas que uma corrente de $25 \mathrm{~A}$ no arco externo reduz a largura e penetração do cordão em relação a soldagem sem corrente no arco externo (MIG/MAG convencional) e, a partir deste valor, o aumento da corrente no arco externo aumenta a largura e penetração do cordão.

As referências que fazem alguma avaliação do perfil do cordão de solda foram feitas sobre uma quantidade de parâmetros bastante limitadas, como pode ser observado anteriormente. Mesmo baseado em poucas condições experimentais, as referências encontradas tratam da influência das correntes (principalmente no arco externo) sobre a geometria, ao passo que nada foi encontrado sobre a influência do comprimento livre de eletrodo e ângulo de ataque da tocha. Desta forma, este trabalho objetiva verificar a influência das correntes de soldagem, mas também do ângulo de ataque da tocha e da distância da tocha entre a peça (fator determinante do comprimento livre do eletrodo) sobre a geometria do cordão de solda.

\section{Procedimento Experimental}

Para avaliar a influência das correntes dos circuitos do arco externo e do arco interno do processo "Plasma-MIG" com arcos concêntricos sobre a geometria do cordão de solda, foram realizadas soldagens de simples deposição sobre chapa ("bead-on-plate"). As condições gerais para a realização destas soldagens foram com o uso de um arame eletrodo de aço ao carbono da classe AWS ER70S-6, de 1,2 mm de diâmetro, Ar como gás interno, a $2 \mathrm{l} / \mathrm{min}$, Ar como gás intermediário, a $8 \mathrm{l} / \mathrm{min}$ e $\mathrm{Ar}+8 \% \mathrm{CO}_{2}$ como gás externo, a $10 \mathrm{l} / \mathrm{min}$. Ambas as fontes reguladas para operar em polaridade positiva (CC+) e com característica estática no modo corrente constante. Nesse modo operacional, a corrente pode ser diretamente regulada conforme desejado.

Já a velocidade de alimentação quando operando no modo corrente constante é dependente da corrente regulada, devendo manter uma relação de tal forma que a essa velocidade seja igual ao consumo de arame, que dependência com a corrente principalmente. Assim valores muito grandes de velocidade de alimentação impedem a formação do arco e muito pequenos fazem o arco crescer até apagar ("burn-back"). Assim, a regulagem com ajuste fino da velocidade de alimentação do arame foi realizada aumentando-se a velocidade de alimentação até que o arame tocasse na poça, gerando curtos-circuitos. A partir desse ponto, a velocidade de alimentação era reduzida suavemente até que o arame deixasse de tocar a poça de fusão e a transferência ocorresse de forma estável.

Como para cada regulagem de corrente (arco interno e externo) se demanda uma velocidade de alimentação e como intencionalmente o volume do cordão por unidade de comprimento foi mantido constante para possibilitar comparações, as regulagens da velocidade de soldagem foram função da velocidade de alimentação encontrada para cada condição (de forma iterativa), para que a relação entre elas fosse constante e o arco o mais curto possível. A relação Velocidade de Soldagem/Velocidade de Alimentação utilizada foi mantida constante em $3 \times 10^{-2}$.

Foram utilizados três níveis de corrente (220, 250 e 280 A) no eletrodo consumível (arco interno) e quatro níveis $(0,40,80$ e 120 A) no arco externo. Os experimentos com nível 0 no fator corrente do arco externo representam em essência uma soldagem MIG/MAG convencional (sem arco externo) com corrente constante utilizando a tocha especial. A influência da distância da tocha a peça e da posição da tocha foram verificadas sob três níveis, $(10,13$ e $16 \mathrm{~mm})$ e (puxando, perpendicular e empurrando), respectivamente. 
A combinação de todos estes parâmetros resultou em 28 condições de soldagem, como mostra a Tabela 1. Nessa tabela, são identificados três grupos de testes, todos tomando como base os testes 5 a 8. No primeiro (testes base acrescidos dos testes 1 a 4 e 9 a 12), foram variadas de forma crescente a corrente no arco externo para cada um dos níveis de corrente no eletrodo consumível, mantendo-se as mesmas distâncias da tocha à peça e inclinação da tocha. No segundo grupo de testes (testes base acrescidos dos testes 13 a 20), procurou-se, ao manter a mesma corrente do eletrodo consumível e inclinação da tocha, se estudar o efeito da Distâncias da Tocha a Peça (DTP) sob diferentes valores de corrente no arco externo. De forma análoga, no terceiro grupo de testes (testes base e testes 21 a 28) foram variadas as inclinações da tocha com o plano vertical ( 0 ,, 15 o puxando e 15 empurrando). Porém, neste último grupo de testes a DTP foi reduzida para as condições puxando e empurrando para se manter um mesmo comprimento livre de eletrodo.

Durante cada experimento foram realizadas as aquisições dos sinais de corrente e tensão para os arcos internos e externos. Para a aquisição da corrente foram utilizados transdutores de corrente que funcionam segundo o princípio do efeito Hall e para a aquisição do valor de tensão foram utilizados divisores de tensão. Para o processo de conversão dos sinais analógicos de corrente e tensão em sinais digitais foi utilizada uma placa de aquisição com uma resolução de 14 bits e com capacidade de operar na faixa de $\pm 10 \mathrm{~V}$. Para uma faixa de medição do sensor Hall de $\pm 500 \mathrm{~A}$, resultou numa resolução de medição, (calculada pela razão: faixa de medição do sensor hall/resolução

Tabela 1. Condições de soldagem para verificação da influência das correntes no eletrodo consumível e no arco externo, da DTP e da inclinação da tocha sobre os parâmetros geométricos do cordão de solda para uma mesma taxa de deposição por unidade de comprimento do cordão.

\begin{tabular}{|c|c|c|c|c|c|c|}
\hline Teste & $\begin{array}{l}\text { Corrente no } \\
\text { Eletrodo } \\
\text { Consumível }[A]\end{array}$ & $\begin{array}{c}\text { Corrente no } \\
\text { Arco Externo } \\
{[\text { [A] }}\end{array}$ & $\begin{array}{c}\text { DTP } \\
\text { [mm] }\end{array}$ & $\begin{array}{l}\text { Inclinação da } \\
\text { tocha com o } \\
\text { plano vertical }\end{array}$ & $\underset{[\mathrm{m} / \mathrm{min}]}{\text { Valim }}$ & $\begin{array}{c}\text { Vsold } \\
{[\mathrm{cm} / \mathrm{min}]}\end{array}$ \\
\hline 1 & 220 & 0 & 10 & $0^{\circ}$ & 6,5 & 19 \\
\hline 2 & 220 & 40 & 10 & $0^{\circ}$ & 7,4 & 22 \\
\hline 3 & 220 & 80 & 10 & $0^{\circ}$ & 8,3 & 25 \\
\hline 4 & 220 & 120 & 10 & $0^{\circ}$ & 8,7 & 26 \\
\hline 5 & 250 & 0 & 10 & $0^{\circ}$ & 6,8 & 20 \\
\hline 6 & 250 & 40 & 10 & $0^{\circ}$ & 8,5 & 26 \\
\hline 7 & 250 & 80 & 10 & $0^{\circ}$ & 9,1 & 27 \\
\hline 8 & 250 & 120 & 10 & $0^{\circ}$ & 9,8 & 29 \\
\hline 9 & 280 & 0 & 10 & $0^{\circ}$ & 8,4 & 26 \\
\hline 10 & 280 & 40 & 10 & $0^{\circ}$ & 10,1 & 31 \\
\hline 11 & 280 & 80 & 10 & $0^{\circ}$ & 10,2 & 31 \\
\hline 12 & 280 & 120 & 10 & $0^{\circ}$ & 10,4 & 32 \\
\hline 13 & 250 & 0 & 13 & $0^{\circ}$ & 7,3 & 22 \\
\hline 14 & 250 & 40 & 13 & $0^{\circ}$ & 9,3 & 28 \\
\hline 15 & 250 & 80 & 13 & $0^{\circ}$ & 10,0 & 30 \\
\hline 16 & 250 & 120 & 13 & $0^{\circ}$ & 10,6 & 32 \\
\hline 17 & 250 & 0 & 16 & $0^{\circ}$ & 8,0 & 24 \\
\hline 18 & 250 & 40 & 16 & $0^{\circ}$ & 10,1 & 30 \\
\hline 19 & 250 & 80 & 16 & $0^{\circ}$ & 10,8 & 32 \\
\hline 20 & 250 & 120 & 16 & $0^{\circ}$ & 11,4 & 36 \\
\hline 21 & 250 & 0 & 10 & $15^{\circ}$ puxando & 6,8 & 20 \\
\hline 22 & 250 & 40 & 10 & $15^{\circ}$ puxando & 8,5 & 26 \\
\hline 23 & 250 & 80 & 10 & $15^{\circ}$ puxando & 9,1 & 27 \\
\hline 24 & 250 & 120 & 10 & $15^{\circ}$ puxando & 9,8 & 29 \\
\hline 25 & 250 & 0 & 10 & $15^{\circ}$ empurrando & 6,8 & 20 \\
\hline 26 & 250 & 40 & 10 & $15^{\circ}$ empurrando & 8,5 & 26 \\
\hline 27 & 250 & 80 & 10 & $15^{\circ}$ empurrando & 9,1 & 27 \\
\hline 28 & 250 & 120 & 10 & $15^{\circ}$ empurrando & 9,8 & 29 \\
\hline
\end{tabular}

Nota: DTP = Distância da Tocha a Peça; Valim = Velocidade de Alimentação; Vsold = Velocidade de Soldagem 
da placa) de 0,06 A para a corrente. De maneira similar, para uma faixa de medição de $\pm 100 \mathrm{~V}$ do divisor de tensão, resulta numa resolução de medição de 0,01 V para a tensão.

Após a execução das soldagens, as placas de teste foram devidamente identificadas para posterior análise. Como cada cordão de solda tem um comprimento de aproximadamente $150 \mathrm{~mm}$, as seções transversais foram tiradas em duas posições, no meio e a aproximadamente $30 \mathrm{~mm}$ do final do cordão. Os corpos de prova foram então lixados e atacados com Nital a 10\% para revelar as macroestruturas dos mesmos. Os parâmetros geométricos foram medidos de acordo com o esquema indicado na Figura 2. Para tanto foi utilizado um software gratuito de processamento de imagens (ImageJ), onde é possível associar uma distância conhecida com o número de pixels correspondente (calibração) e a partir de então, realizar medições lineares e de área.

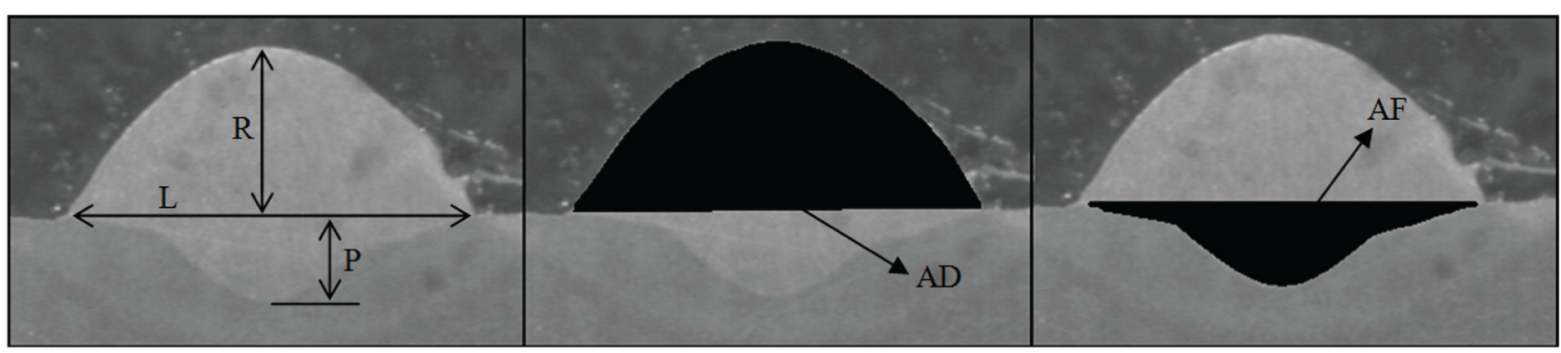

Figura 2. Parâmetros geométricos medidos nos cordões: $L=$ Largura; $R=$ Reforço; $P=$ Penetração; $A F=$ Área Fundida e AD = Área Depositada.

\section{Resultados e Discussões}

Na Tabela 2 estão apresentados os valores médios, com seus respectivos desvios padrões, dos sinais de corrente e tensão monitorados para os circuitos relativos ao arco interno e externo de cada um dos experimentos apresentados na Tabela 1. Para o cálculo destes valores foram consideradas as aquisições de todo o período que o arco ficou aberto para a execução da solda, com exceção ao período de abertura do arco. Também é mostrado na mesma tabela, a potência elétrica total consumida, calculada como a somatória entre o produto da corrente (I) e da tensão (V) para cada arco $\left(P=I_{\text {Arco Interno }} . V_{\text {Arco Interno }}+I_{\text {Arco Externo }} . V_{\text {Arco Externo }}\right)$, e a energia total de soldagem, dividindo a potência pela velocidade linear de soldagem.

Tabela 2. Valores médios de corrente e tensão dos circuitos do arco interno e do arco externo (DTP e inclinação da tocha variam conforme Tabela 1).

\begin{tabular}{|c|c|c|c|c|c|c|c|}
\hline Teste & $\begin{array}{c}\text { Corrente } \\
\text { no Eletrodo } \\
\text { Consumível } \\
\text { [A] }\end{array}$ & $\begin{array}{c}\text { Tensão no } \\
\text { Eletrodo } \\
\text { Consumível } \\
\text { [V] }\end{array}$ & $\begin{array}{c}\text { Corrente } \\
\text { no Arco } \\
\text { Externo [A] }\end{array}$ & $\begin{array}{c}\text { Tensão no } \\
\text { Arco } \\
\text { Externo [V] }\end{array}$ & $\begin{array}{c}\text { Potência } \\
\text { (W) }\end{array}$ & $\begin{array}{c}\text { Energia de } \\
\text { Soldagem } \\
{[\mathrm{kJ} / \mathrm{mm}]}\end{array}$ & Seção transversal \\
\hline 1 & $220,7^{ \pm 3,9}$ & $30,4^{ \pm 1,0}$ & - & - & 6709 & 2,12 & \\
\hline 2 & $220,1^{ \pm 4,0}$ & $27,6^{ \pm 1,2}$ & $40,1^{ \pm 1,9}$ & $37,5^{ \pm 2,8}$ & 7579 & 2,07 & \\
\hline 3 & $220,4^{ \pm 4,1}$ & $29,6^{ \pm 1,5}$ & $79,2^{ \pm 1,9}$ & $33,1^{ \pm 2,5}$ & 9145 & 2,19 & \\
\hline
\end{tabular}

Nota: Os valores sobrescritos para a corrente e tensão correspondem aos desvios padrões das medições. 
Tabela 2. Continuação...

\begin{tabular}{|c|c|c|c|c|c|c|c|}
\hline Teste & $\begin{array}{c}\text { Corrente } \\
\text { no Eletrodo } \\
\text { Consumível } \\
\text { [A] }\end{array}$ & $\begin{array}{c}\text { Tensão no } \\
\text { Eletrodo } \\
\text { Consumível } \\
\text { [V] }\end{array}$ & $\begin{array}{c}\text { Corrente } \\
\text { no Arco } \\
\text { Externo [A] }\end{array}$ & $\begin{array}{c}\text { Tensão no } \\
\text { Arco } \\
\text { Externo [V] }\end{array}$ & $\begin{array}{l}\text { Potência } \\
\text { (W) }\end{array}$ & $\begin{array}{c}\text { Energia de } \\
\text { Soldagem } \\
\text { [kJ/mm] }\end{array}$ & Seção transversal \\
\hline 4 & $220,4^{ \pm 4,0}$ & $28,7^{ \pm 1,4}$ & $118,4^{ \pm 2,0}$ & $37,5^{ \pm 3,2}$ & 10765 & 2,48 & \\
\hline 5 & $250,6^{ \pm 3,9}$ & $27,7^{ \pm 1,7}$ & - & - & 6942 & 2,08 & \\
\hline 6 & $251,1^{ \pm 4,0}$ & $26,5^{ \pm 1,1}$ & $40,2^{ \pm 1,9}$ & $30,8^{ \pm 2,9}$ & 7892 & 1,82 & \\
\hline 7 & $250,3^{ \pm 4,0}$ & $28,9^{ \pm 1,5}$ & $79,4^{ \pm 1,9}$ & $35,1^{ \pm 2,1}$ & 10021 & 2,23 & \\
\hline 8 & $250,5^{ \pm 4,0}$ & $25,0^{ \pm 1,2}$ & $117,3^{ \pm 1,8}$ & $33,4^{ \pm 2,5}$ & 10180 & 2,11 & \\
\hline 9 & $280,1^{ \pm 4,1}$ & $26,1^{ \pm 1,9}$ & - & - & 7311 & 1,69 & \\
\hline 10 & $281,1^{ \pm 4,0}$ & $27,8^{ \pm 1,6}$ & $40,6^{ \pm 2,0}$ & $34,9^{ \pm 3,1}$ & 9232 & 1,79 & \\
\hline 11 & $281,8^{ \pm 3,9}$ & $28,3^{ \pm 1,4}$ & $80,2^{ \pm 1,8}$ & $36,1^{ \pm 2,9}$ & 10870 & 2,10 & \\
\hline 12 & $280,6^{ \pm 3,9}$ & $25,0^{ \pm 1,8}$ & $117,5^{ \pm 1,8}$ & $35,7^{ \pm 3,5}$ & 11210 & 2,10 & \\
\hline 13 & $251,1^{ \pm 4,0}$ & $24,7^{ \pm 1,7}$ & - & - & 6202 & 1,69 & \\
\hline 14 & $250,9^{ \pm 4,0}$ & $28,7^{ \pm 1,6}$ & $40,2^{ \pm 2,1}$ & $39,1^{ \pm 2,8}$ & 8773 & 1,88 & \\
\hline 15 & $251,3^{ \pm 3,9}$ & $26,9^{ \pm 1,7}$ & $79,4^{ \pm 1,9}$ & $37,8^{ \pm 3,1}$ & 9761 & 1,95 & \\
\hline
\end{tabular}

Nota: Os valores sobrescritos para a corrente e tensão correspondem aos desvios padrões das medições. 
Influência dos Níveis das Correntes, Ângulo de Inclinação da Tocha e Distância entre a Tocha e a Peça sobre a Geometria do Cordão de Solda Usando "Plasma-MIG" com Arcos Concêntricos

Tabela 2. Continuação...

\begin{tabular}{|c|c|c|c|c|c|c|c|}
\hline Teste & $\begin{array}{c}\text { Corrente } \\
\text { no Eletrodo } \\
\text { Consumível } \\
\text { [A] }\end{array}$ & $\begin{array}{c}\text { Tensão no } \\
\text { Eletrodo } \\
\text { Consumível } \\
\text { [V] }\end{array}$ & $\begin{array}{c}\text { Corrente } \\
\text { no Arco } \\
\text { Externo [A] }\end{array}$ & $\begin{array}{c}\text { Tensão no } \\
\text { Arco } \\
\text { Externo [V] }\end{array}$ & $\begin{array}{l}\text { Potência } \\
\text { (W) }\end{array}$ & $\begin{array}{c}\text { Energia de } \\
\text { Soldagem } \\
\text { [kJ/mm] }\end{array}$ & Seção transversal \\
\hline 16 & $250,4^{ \pm 4,0}$ & $27,4^{ \pm 1,3}$ & $118,1^{ \pm 2,0}$ & $38,4^{ \pm 2,8}$ & 11396 & 2,14 & \\
\hline 17 & $251,1^{ \pm 3,9}$ & $24,7^{ \pm 2,0}$ & - & - & 6202 & 1,55 & \\
\hline 18 & $250,9^{ \pm 4,0}$ & $28,7^{ \pm 1,2}$ & $40,4^{ \pm 2,2}$ & $40,1^{ \pm 2,9}$ & 8821 & 1,76 & \\
\hline 19 & $251,3^{ \pm 4,0}$ & $26,9^{ \pm 1,5}$ & $78,9^{ \pm 2,1}$ & $41,4^{ \pm 2,1}$ & 10026 & 1,88 & \\
\hline 20 & $250,4^{ \pm 4,0}$ & $27,4^{ \pm 1,8}$ & $119,1^{ \pm 2,2}$ & $39,7^{ \pm 2,4}$ & 11589 & 1,93 & \\
\hline 21 & $250,6^{ \pm 4,1}$ & $26,7^{ \pm 1,0}$ & - & - & 6691 & 2,01 & \\
\hline 22 & $250,4^{ \pm 4,0}$ & $27,5^{ \pm 1,6}$ & $40,1^{ \pm 2,0}$ & $34,3^{ \pm 2,7}$ & 8261 & 1,91 & \\
\hline 23 & $250,8^{ \pm 4,0}$ & $26,3^{ \pm 1,7}$ & $79,4^{ \pm 1,9}$ & $36,1 \pm 3,0$ & 9462 & 2,10 & \\
\hline 24 & $250,1^{ \pm 3,9}$ & $26,2^{ \pm 1,5}$ & $119,3^{ \pm 1,9}$ & $34,2^{ \pm 2,0}$ & 10633 & 2,20 & \\
\hline 25 & $250,3^{ \pm 3,8}$ & $27,9^{ \pm 1,5}$ & - & - & 6983 & 2,10 & \\
\hline 26 & $250,1^{ \pm 3,9}$ & $24,4^{ \pm 1,3}$ & $41,4^{ \pm 1,8}$ & $30,8^{ \pm 2,3}$ & 7378 & 1,70 & \\
\hline 27 & $251,2^{ \pm 3,9}$ & $26,3^{ \pm 1,5}$ & $80,0^{ \pm 1,8}$ & $35,1^{ \pm 2,8}$ & 9415 & 2,09 & \\
\hline 28 & $250,3^{ \pm 4,0}$ & $26,8^{ \pm 1,2}$ & $116,1^{ \pm 1,9}$ & $34,4^{ \pm 2,5}$ & 10702 & 2,21 & \\
\hline
\end{tabular}

Nota: Os valores sobrescritos para a corrente e tensão correspondem aos desvios padrões das medições. 
Deve ser observado que as correntes possuem um papel muito importante no cálculo da energia de soldagem para experimentos onde são mantidas constantes as relações entre velocidade de soldagem e velocidade de alimentação. Isto ocorre porque uma variação na corrente de soldagem interfere no valor da velocidade de alimentação do eletrodo consumível, que por sua vez, altera o valor da velocidade de soldagem (utilizado no cálculo da energia de soldagem). Ou seja, a variação na corrente afeta ao mesmo tempo o cálculo da potência e da velocidade de soldagem, que afetam em sentidos opostos o cálculo da energia de soldagem. A Figura 3 mostra que o aumento da corrente do arco externo apresenta uma tendência de aumentar a energia de soldagem, já a corrente no arco externo também apresenta uma tendência de aumentar a energia de soldagem, no entanto, ela não é tão evidente. Considerando que a taxa de deposição por unidade de comprimento de solda foi o mesmo, isto mostra que a as correntes dos arcos interno e externo afetam a taxa de deposição de forma não linear (fazem crescer em maior gradiente do que elas). Mas que o efeito das correntes dos arcos externo e internos só de manifestam a partir do $40 \mathrm{~A}$. De qualquer forma, a energia de soldagem afeta diretamente (mesmo eu não linearmente) o calor imposto sobre a chapa. A Figura 4 mostra que também a DTP influencia a energia imposta. É de conhecimento geral que para maiores DTP (consequentemente, maiores comprimentos de eletrodos livres), a corrente se torna menor para se manter a mesma taxa de deposição. Mas como no presente caso a corrente foi a mesma, maior se torna a taxa de fusão para maiores comprimentos livres de eletrodos (consequentemente, para manutenção da mesma taxa de deposição por unidade de comprimento, menor energia de soldagem). Por outro lada, a Figura 5 mostra que não se percebe uma tendência para o efeito do posicionamento da tocha sobre a energia de soldagem, o que seria esperado, já que procurou-se manter para os 3 casos o mesmo comprimento livre de eletrodo.

Também é importante pontuar que a energia de soldagem gerada pelos arcos não necessariamente é transferida para a chapa (calor imposto), podendo, parte dela, ser perdida para o meio ambiente. O cálculo do calor

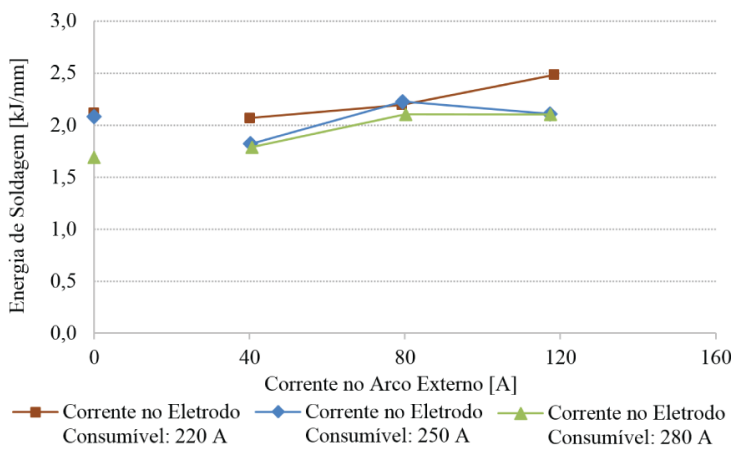

Figura 3. Energia de soldagem do processo "Plasma-MIG" com Arcos Concêntricos em função da corrente no arco externo para três valores de corrente no eletrodo consumível, DTP de $10 \mathrm{~mm}$ e tocha reta.

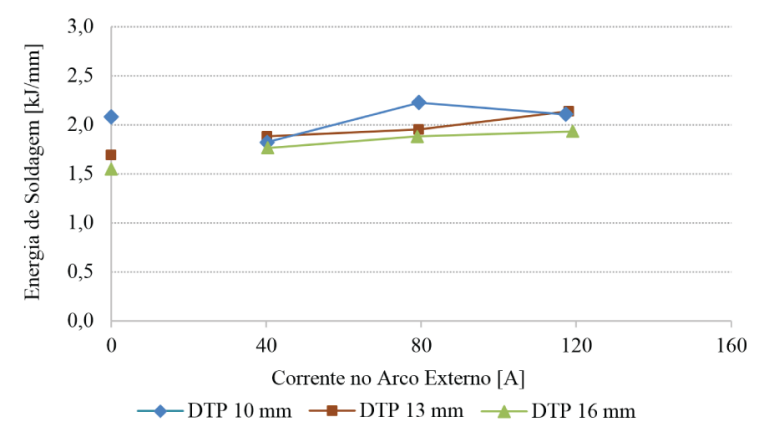

Figura 4. Energia de soldagem do processo "Plasma-MIG" com Arcos Concêntricos em função da corrente no arco externo para três valores de DTP, corrente no arco interno de $250 \mathrm{~A}$ e tocha reta. imposto (efetivamente transferido para a chapa), por sua vez, depende do rendimento térmico. Sabendo disso, algumas ponderações devem ser feitas. Quando o arco externo está presente, o mesmo possui provavelmente um rendimento térmico menor, já que o mesmo possui uma área lateral de perda de calor para o ambiente consideravelmente maior, se comparado ao arco interno. Por outro lado, o arco externo deve funcionar como um isolante para o arco interno, aumentando seu rendimento térmico do último.

Os valores médios dos parâmetros geométricos do cordão de solda medidos, com os respectivos desvios padrões, estão apresentados na Tabela 3. Para melhorar a apresentação dos resultados e facilitar a análise do

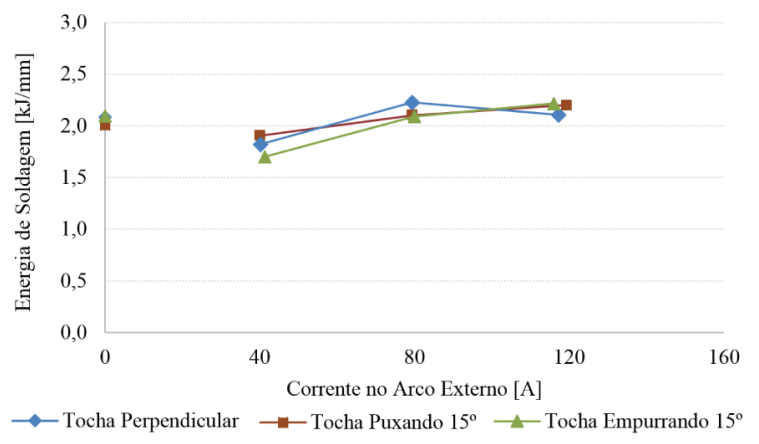

Figura 5. Energia de soldagem do processo "Plasma-MIG" com Arcos Concêntricos em função da corrente no arco externo para três valores de inclinação da tocha, DTP de 10 mm e corrente no arco interno de 250 . 
comportamento do processo, esses parâmetros foram dispostos individualmente em forma de gráficos, que são apresentados na sequência. É importante ressaltar que não parece ter muito sentido a interpolação dos resultados entre as condições sem corrente no arco externo e com corrente no arco externo, pois são dois processos diferentes. Assim, a análise será realizada pelo efeito da corrente no arco externo variando de 40 a $120 \mathrm{~A}$, sob o efeito da variação da corrente no arco interno, comparativamente a uma condição do processo MIG/MAG convencional, apenas com o arco interno.

\subsection{Efeito da corrente no arco externo}

Na Figura 6a, pode-se verificar uma tendência de aumento da largura do cordão de solda com o aumento da corrente no externo, independentemente da corrente no eletrodo consumível. Há também uma tendência do aumento da largura quando se aumenta a corrente no eletrodo consumível, para uma dada corrente no arco externo e um mesmo volume de material depositado por unidade de comprimento. De forma coerente, é possível observar na Figura $6 \mathrm{~b}$ uma leve tendência de redução no reforço do cordão de solda com o aumento da corrente no arco externo e no eletrodo consumível (para uma mesma taxa de deposição por unidade de comprimento de solda, o aumento da largura do cordão faz reduzir o reforço). Todos estes resultados estão de acordo com [1,2,5,6].

Tabela 3. Parâmetros geométricos medidos para os cordões de solda com desvio padrão relativo a duas medições (DTP e inclinação da tocha variam conforme Tabela 1).

\begin{tabular}{|c|c|c|c|c|c|}
\hline Teste & $\begin{array}{c}\text { Largura } \\
{[\mathrm{mm}]}\end{array}$ & $\begin{array}{l}\text { Reforço } \\
\text { [mm] }\end{array}$ & $\begin{array}{l}\text { Penetração } \\
\text { [mm] }\end{array}$ & $\begin{array}{c}\text { Área Fundida } \\
{\left[\mathrm{mm}^{2}\right]}\end{array}$ & $\begin{array}{c}\text { Área Depositada } \\
{\left[\mathrm{mm}^{2}\right]}\end{array}$ \\
\hline 1 & $12,1^{ \pm 0,8}$ & $4,4^{ \pm 0,4}$ & $2,8^{ \pm 0,4}$ & $21,8^{ \pm 4,6}$ & $37,9 \pm 2,1$ \\
\hline 2 & $12,8^{ \pm 0,1}$ & $4,4^{ \pm 0,4}$ & $2,6^{ \pm 0,1}$ & $17,2^{ \pm 1,8}$ & $41,1^{ \pm 0,8}$ \\
\hline 3 & $13,1^{ \pm 0,4}$ & $4,3^{ \pm 0,2}$ & $2,9^{ \pm 0,1}$ & $21,8^{ \pm 0,8}$ & $41,6^{ \pm 3,2}$ \\
\hline 4 & $14,3^{ \pm 0,8}$ & $4,3^{ \pm 0,2}$ & $3,2^{ \pm 0,1}$ & $19,7^{ \pm 0,7}$ & $40,7^{ \pm 1,4}$ \\
\hline 5 & $13,4^{ \pm 0,1}$ & $4,2^{ \pm 0,1}$ & $3,3^{ \pm 0,1}$ & $26,5^{ \pm 2,1}$ & $41,3^{ \pm 1,1}$ \\
\hline 6 & $13,7^{ \pm 0,1}$ & $4,0^{ \pm 0,1}$ & $2,8^{ \pm 0,3}$ & $21,5^{ \pm 2,1}$ & $37,9^{ \pm 1,5}$ \\
\hline 7 & $15,3^{ \pm 0,7}$ & $3,8^{ \pm 0,1}$ & $3,2^{ \pm 0,4}$ & $24,9^{ \pm 1,6}$ & $39,4^{ \pm 0,9}$ \\
\hline 8 & $16,3^{ \pm 0,4}$ & $3,8^{ \pm 0,1}$ & $3,8^{ \pm 0,1}$ & $24,1 \pm 1,2$ & $41,3^{ \pm 1,0}$ \\
\hline 9 & $14,4^{ \pm 0,1}$ & $3,9^{ \pm 0,4}$ & $3,7^{ \pm 0,3}$ & $32,3^{ \pm 1,0}$ & $37,5^{ \pm 4,4}$ \\
\hline 10 & $15,4^{ \pm 0,1}$ & $4,0^{ \pm 0,1}$ & $3,2^{ \pm 0,3}$ & $24,1 \pm 5,2$ & $41,6^{ \pm 0,5}$ \\
\hline 11 & $16,4^{ \pm 0,3}$ & $3,7^{ \pm 0,1}$ & $3,5^{ \pm 0,5}$ & $27,9^{ \pm 3,9}$ & $42,3^{ \pm 0,6}$ \\
\hline 12 & $16,5^{ \pm 1,0}$ & $3,8^{ \pm 0,1}$ & $4,0^{ \pm 0,2}$ & $31,4^{ \pm 3,6}$ & $41,4^{ \pm 0,8}$ \\
\hline 13 & $13,1^{ \pm 0,1}$ & $4,2^{ \pm 0,1}$ & $3,3^{ \pm 0,2}$ & $26,8^{ \pm 1,6}$ & $40,1^{ \pm 2,8}$ \\
\hline 14 & $12,6^{ \pm 0,4}$ & $4,3^{ \pm 0,1}$ & $2,8^{ \pm 0,3}$ & $17,9^{ \pm 1,1}$ & $38,9^{ \pm 2,6}$ \\
\hline 15 & $13,7^{ \pm 0,1}$ & $4,1^{ \pm 0,1}$ & $3,1^{ \pm 0,2}$ & $19,3^{ \pm 1,2}$ & $39,3^{ \pm 0,3}$ \\
\hline 16 & $14,4^{ \pm 0,5}$ & $4,0^{ \pm 0,1}$ & $3,3^{ \pm 0,1}$ & $21,2^{ \pm 3,2}$ & $39,8^{ \pm 2,1}$ \\
\hline 17 & $12,9^{ \pm 0,2}$ & $4,3^{ \pm 0,1}$ & $3,2^{ \pm 0,1}$ & $23,4^{ \pm 1,1}$ & $38,7^{ \pm 2,4}$ \\
\hline 18 & $12,4^{ \pm 0,1}$ & $4,5^{ \pm 0,1}$ & $2,7^{ \pm 0,4}$ & $16,0^{ \pm 1,3}$ & $39,2^{ \pm 3,9}$ \\
\hline 19 & $13,0^{ \pm 0,9}$ & $4,3^{ \pm 0,2}$ & $3,1^{ \pm 0,2}$ & $16,7^{ \pm 1,1}$ & $41,0^{ \pm 4,4}$ \\
\hline 20 & $13,2^{ \pm 0,6}$ & $4,2^{ \pm 0,1}$ & $3,5^{ \pm 0,1}$ & $18,9^{ \pm 1,9}$ & $36,5^{ \pm 3,9}$ \\
\hline 21 & $12,9^{ \pm 0,6}$ & $4,4^{ \pm 0,2}$ & $3,5^{ \pm 0,3}$ & $23,5^{ \pm 0,7}$ & $37,7^{ \pm 5,1}$ \\
\hline 22 & $13,2^{ \pm 0,3}$ & $4,3^{ \pm 0,2}$ & $3,3^{ \pm 0,1}$ & $21,0^{ \pm 1,4}$ & $39,9^{ \pm 0,3}$ \\
\hline 23 & $14,6^{ \pm 0,1}$ & $4,2^{ \pm 0,1}$ & $3,8^{ \pm 0,4}$ & $24,0^{ \pm 1,5}$ & $42,3^{ \pm 2,1}$ \\
\hline 24 & $14,9^{ \pm 0,1}$ & $4,0^{ \pm 0,1}$ & $4,0^{ \pm 0,4}$ & $25,2^{ \pm 4,0}$ & $39,7 \pm 2,0$ \\
\hline 25 & $14,0^{ \pm 1,0}$ & $3,9^{ \pm 0,2}$ & $3,0^{ \pm 0,7}$ & $23,5^{ \pm 0,7}$ & $40,1^{ \pm 0,6}$ \\
\hline 26 & $15,2^{ \pm 0,1}$ & $3,7^{ \pm 0,2}$ & $2,7^{ \pm 0,1}$ & $21,6^{ \pm 2,3}$ & $40,7^{ \pm 0,9}$ \\
\hline 27 & $16,4^{ \pm 0,1}$ & $3,6^{ \pm 0,2}$ & $3,0^{ \pm 0,1}$ & $24,0^{ \pm 1,4}$ & $40,5^{ \pm 0,4}$ \\
\hline 28 & $16,7^{ \pm 0,4}$ & $3,5^{ \pm 0,1}$ & $3,2^{ \pm 0,1}$ & $25,8^{ \pm 2,9}$ & $39,0^{ \pm 0,7}$ \\
\hline
\end{tabular}

Nota: Os valores sobrescritos para a corrente e tensão correspondem aos desvios padrões das medições. 

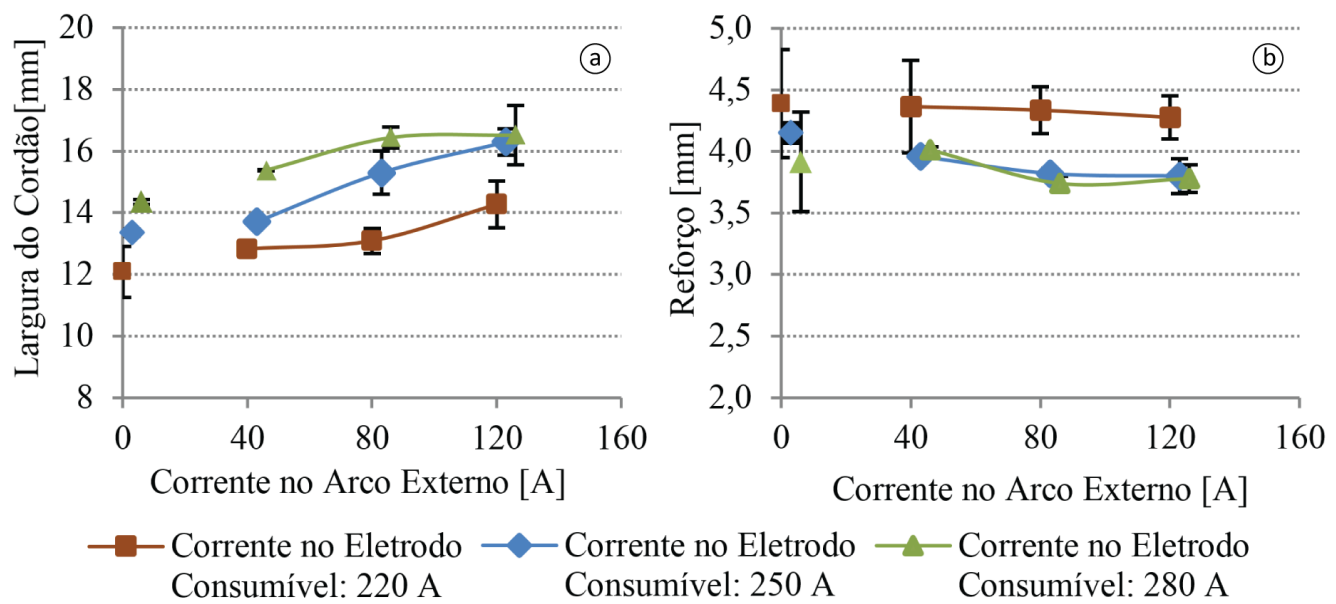

Figura 6. Largura (a) e Reforço (b) do cordão de solda para o processo "Plasma-MIG" com Arcos Concêntricos em função da corrente no arco externo para três valores de corrente no eletrodo consumível, DTP de $10 \mathrm{~mm}$ e tocha posicionada perpendicularmente (alguns pontos foram levemente deslocados na horizontal para permitir a visualização das barras de erro).

Quando a solda é realizada sem a presença do arco externo, o aquecimento do metal de base é resultado apenas do arco interno (processo MIG/MAG convencional). Assim, a adição de corrente no arco externo provoca maior aquecimento da chapa (maior energia), consequentemente favorecendo a molhabilidade (a largura do cordão aumenta). Quanto maior essa corrente, maior o seu efeito. Efeito similar acontece quando a corrente no arco interno é aumentada no processo; o arco formado aumenta a área de contato com a peça, que por consequência, aumenta a área da superfície da chapa aquecida, aumentando a molhabilidade da mesma, resultando em cordões mais largos.

As Figura 7a, b, que se referem respectivamente à penetração e área fundida. No que diz respeito a penetração, pela Figura 7a podem ser observados dois momentos, num primeiro, ao se adicionar a corrente externa com valores bem baixos (40 A), a penetração reduz. É importante lembrar que, pela Figura 3, para essa corrente não houve aumento da energia de soldagem. Uma possibilidade para explicar o comportamento é que a área de acoplamento do arco cresce, reduzindo a concentração da corrente, dificultando a fusão no sentido da espessura. Outra possibilidade pode estar relacionada com a força do jato de plasma, que pode ter se reduzido também como uma consequência do aumento do volume do arco, principalmente na região do arame. Ainda outra explicação é encontrada nos resultados de [7], os quais verificaram que a presença do arco externo reduz o calor que é imposto à chapa, para uma mesma corrente total (não possível de verificar neste trabalho). Essers e Walter [7] associaram a maior perda de calor ao sistema de refrigeração do eletrodo não consumível. Esta redução de calor imposto observada pode ser também consequência do aumento de área total do arco provocado pelo arco externo (neste caso, a concentração de calor na chapa é reduzida, dificultando a penetração). Todos esses mecanismos, atuando em conjunto, levam como consequência à redução da penetração do cordão de solda para corrente externa em valores baixos (40 A). No segundo momento, ao se aumentar a corrente no arco externo, esses efeitos vão se contrabalançando com o do aumento da energia, que mesmo menos concentrada passa a ser maior; assim, a penetração e área fundida aumentam proporcionalmente com a corrente externa.

Ainda na Figura 7a, pode se observar um aumento na penetração com o aumento da corrente no arco interno (maior energia) independentemente da corrente externa (similarmente ao efeito sobre a largura e reforço), demonstrando que o efeito da corrente no arco externo age de forma independente.

Em relação a penetração e a área fundida, respectivamente Figura $7 a$, b, são esperados comportamentos similares, uma vez que ambos os parâmetros são governados majoritariamente pelos mesmos mecanismos. Assim, a análise já apresentada para a penetração é válida também para a área fundida. No entanto, a área fundida apresentou uma diferença de comportamento em relação a penetração para correntes no eletrodo consumível de 220 A e 250 A. Esta diferença pode ser entendida ao observar as seções transversais mostradas na Figura 2, 
Influência dos Níveis das Correntes, Ângulo de Inclinação da Tocha e Distância entre a Tocha e a Peça sobre a Geometria do Cordão de Solda Usando "Plasma-MIG" com Arcos Concêntricos

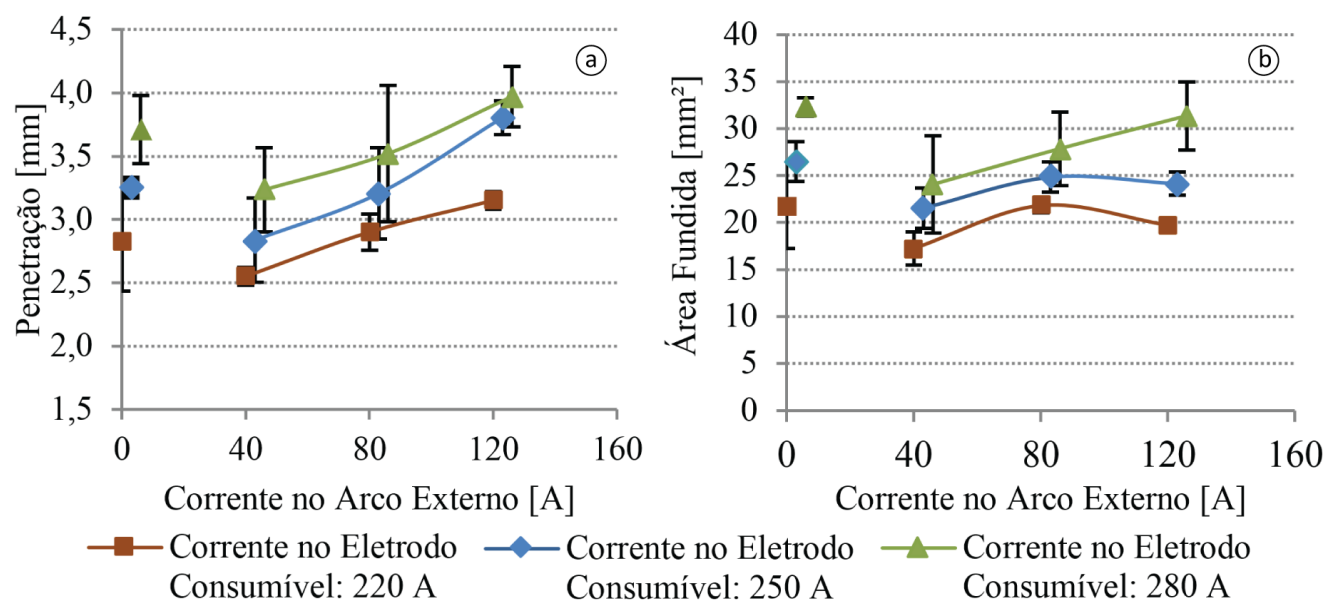

Figura 7. Penetração (a) e Área Fundida (b) do cordão de solda para o processo "Plasma-MIG" com Arcos Concêntricos em função da corrente no arco externo para três valores de corrente no eletrodo consumível, DTP de $10 \mathrm{~mm}$ e tocha posicionada perpendicularmente (alguns pontos foram levemente deslocados na horizontal para permitir a visualização das barras de erro).

onde para correntes no arco externo acima de $80 \mathrm{~A}$ foi verificado um evidenciamento do perfil de penetração do tipo "cálice" que favorece o aumento da penetração, mas não favorece o aumento da área fundida.

\subsection{Efeito da distância da tocha a peça}

Os efeitos da corrente no arco externo já foram avaliados no item 3.1 onde todas as soldas foram realizadas com DTP de $10 \mathrm{~mm}$. Desta forma, o foco da análise para este item serão os efeitos da variação da distância da tocha a peça sobre a geometria do cordão de solda.

Como o comprimento do arco foi mantido aproximadamente constante, maiores DTP implicam em um maior comprimento livre de eletrodo, o que demanda uma maior velocidade de alimentação do arame para se alcançar os mesmos valores de corrente. Para manter a relação entre velocidade de soldagem e velocidade de alimentação constante, foi necessário, então, aumentar a velocidade de soldagem, resultando em um menor aquecimento do metal de base por unidade de comprimento (reduzindo a energia de soldagem), com reflexos sobre a molhabilidade (cordões mais convexos e com menores larguras). Assim, como apresenta a Figura 8a, a tendência de se obter maiores larguras de cordão para menores DTP fica mais evidenciada. Deve-se destacar que o efeito de aumentar a largura em função do aumento da corrente no arco externo é contrabalanceado com o efeito de reduzir a largura em função da maior velocidade de soldagem. Na Figura $8 \mathrm{~b}$ é observado para o reforço um comportamento oposto ao verificado para largura, uma vez que todos os cordões de solda possuem o mesmo volume e estes dois parâmetros geométricos são regidos pelos mesmos mecanismos.

Na Figura 9a é observado que o aumento da DTP influi muito pouco sobre a penetração, sendo que o efeito da corrente no arco externo já mostrada na Figura 7a. Há apenas uma tendência de haver maior penetração para a menor DTP em valores maiores de corrente externa. Mas, como ilustra a Figura 9b, o efeito da DTP é mais nítido quando se analisa o comportamento da corrente externa sobre a área fundida. Apesar de não se mudar as tendências do efeito da corrente externa sobre a penetração, já apontadas na Figura 7b, quanto maior a DTP, menor se torna a área fundida. Esta redução na área fundida apresenta uma forte relação com a energia de soldagem, ao observar a Tabela 2, as menores energias de soldagem estão associadas justamente às maiores DTPs, que por sua vez, produziram soldas com menores áreas fundidas.

\subsection{Efeito da inclinação da tocha}

O ângulo da tocha influi sobre os valores de largura, reforço, penetração e área fundida. Pode-se perceber pela Figura 10a que com a tocha (arco) empurrando produz cordões com maior largura, invertendo a tendência 

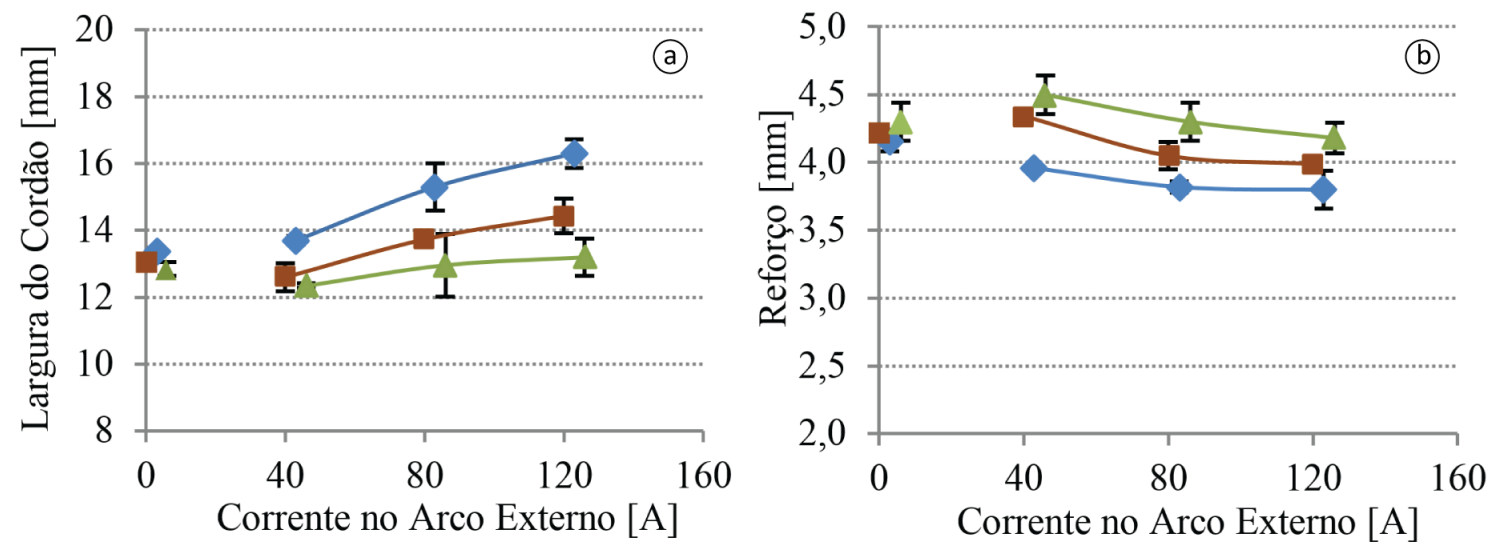

$\multimap$ DTP $10 \mathrm{~mm} \longrightarrow$ DTP $13 \mathrm{~mm} \multimap$ DTP $16 \mathrm{~mm}$

Figura 8. Largura (a) e Reforço (b) do cordão de solda para o processo “Plasma-MIG" com Arcos Concêntricos em função da corrente no arco externo para três Distâncias entre a Tocha e a Peça (DTP), corrente no arco interno de 250 A e tocha posicionada perpendicularmente (alguns pontos foram levemente deslocados na horizontal para permitir a visualização das barras de erro).
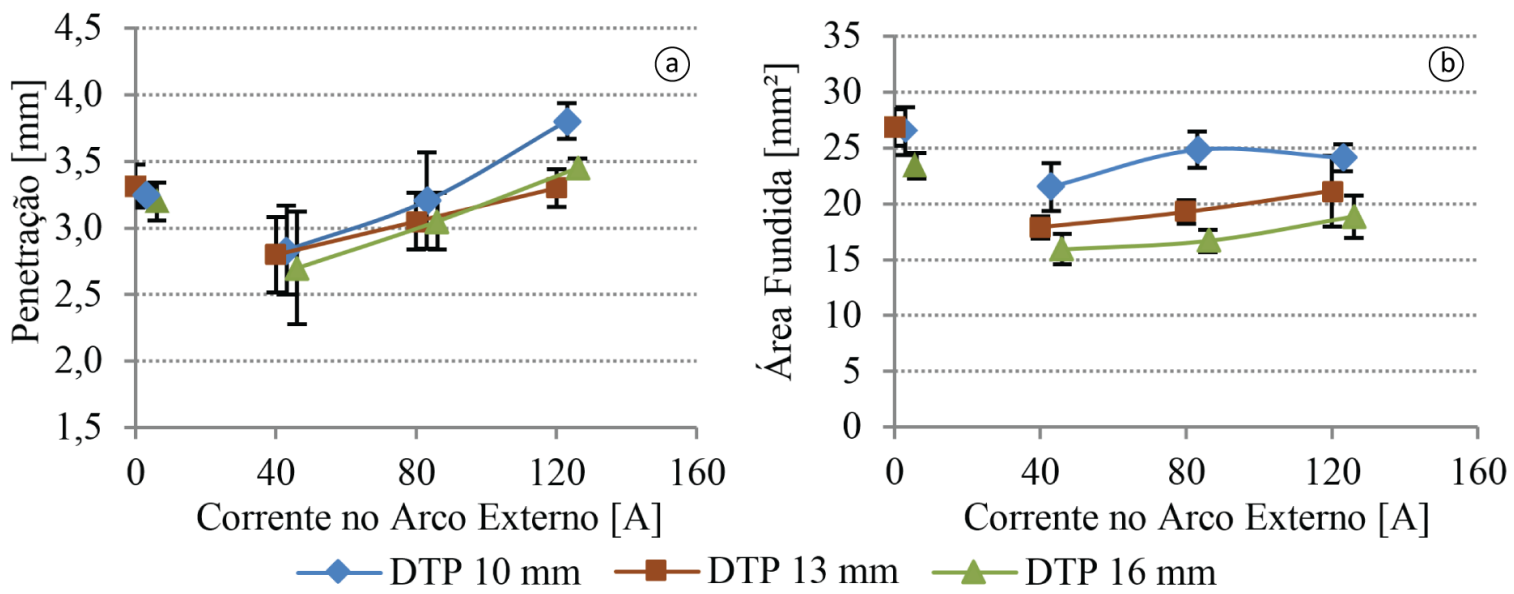

Figura 9. Penetração (a) e Área Fundida (b) do cordão de solda para o processo "Plasma-MIG" com Arcos Concêntricos em função da corrente no arco externo para três Distâncias entre a Tocha e a Peça (DTP), corrente no arco interno de $250 \mathrm{~A}$ e tocha posicionada perpendicularmente (alguns pontos foram levemente deslocados na horizontal para permitir a visualização das barras de erro).

com a tocha puxando. Considerando que a energia do arco foi a mesma, isto acontece devido ao pré-aquecimento que o arco provoca à frente da poça fundida quando o arco está empurrando, aumentando a molhabilidade e favorecendo o aumento da largura do cordão. Quando corrente no arco externo é adicionada ao processo, a largura aumenta para as três condições de inclinação da tocha, como resultado do aumento da energia acrescentada ao processo. A Figura $10 \mathrm{~b}$ mostra a variação do reforço do cordão de solda que apresenta um comportamento oposto ao verificado na largura, uma vez que todos os cordões de solda possuem o mesmo volume e estes dois parâmetros geométricos são regidos pelos mesmos mecanismos.

Na Figura 11a é possível observar um aumento na penetração à medida que a tocha passa de empurrando para puxando. Este efeito pode ser justificado pelo fato do jato de plasma empurrar a poça fundida para trás no 


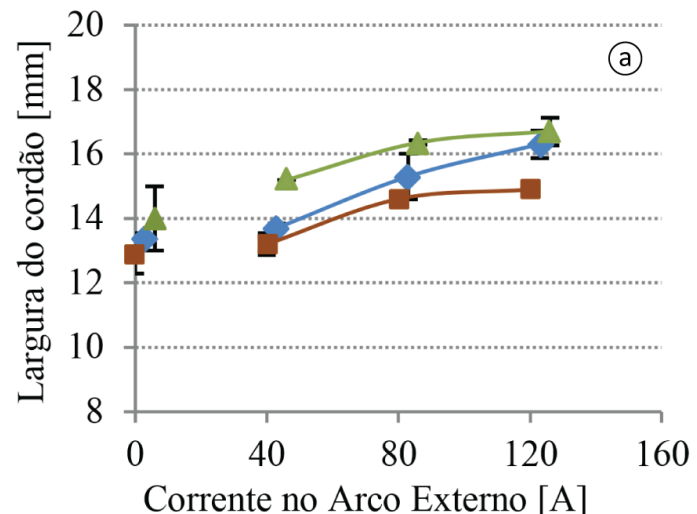

Corrente no Arco Externo [A]

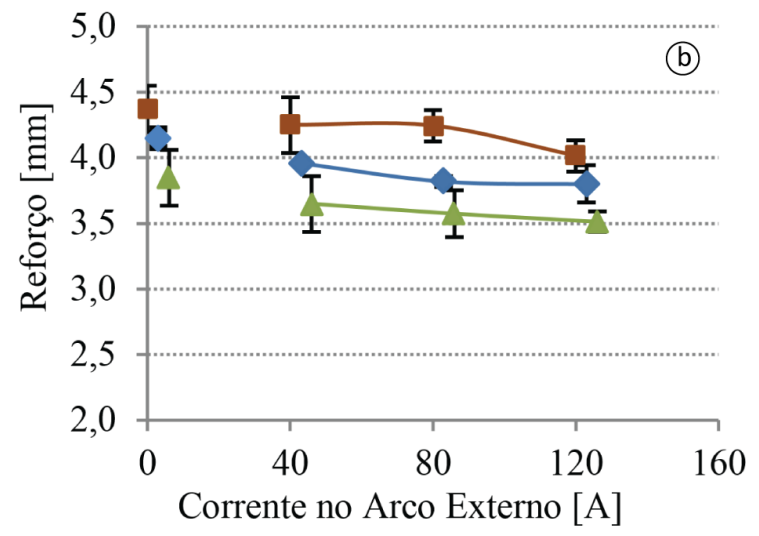

Corrente no Arco Externo $[\mathrm{A}]$

$\neg$ Tocha Perpendicular $\longrightarrow$ Tocha Puxando $15^{\circ} \longrightarrow$ Tocha Empurrando $15^{\circ}$

Figura 10. Largura (a) e Reforço (b) do cordão de solda para o processo "Plasma-MIG" com Arcos Concêntricos em função da corrente no arco externo para três posições de Inclinação da tocha, DTP de $10 \mathrm{~mm}$ e corrente no arco interno de $250 \mathrm{~A}$ (alguns pontos foram levemente deslocados na horizontal para permitir a visualização das barras de erro).

modo puxando, de tal forma que o aquecimento da chapa pelo acoplamento do arco com a peça se torna mais eficiente (age mais no fundo da poça). Além disso, existe a ação das gotas em transferência diretamente para a região mais aquecida da chapa, localizada no fundo da poça.

Em relação à área fundida, a princípio era de se esperar um comportamento similar ao observado para a penetração nos resultados mostrados na Figura 11b. No entanto, as curvas estão praticamente sobrepostas, o que pode ser entendido ao observar a Figura 12, que mostra que na condição puxando o perfil do cordão de solda foi alterado progressivamente de um formato do tipo "prato fundo" para o do tipo "cálice", que favorece o aumento da penetração, mas com pouco efeito sobre a área fundida.

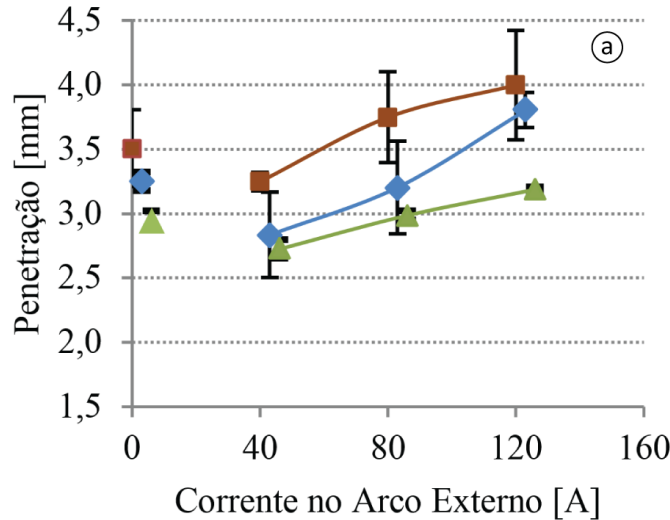

Corrente no Arco Externo [A]

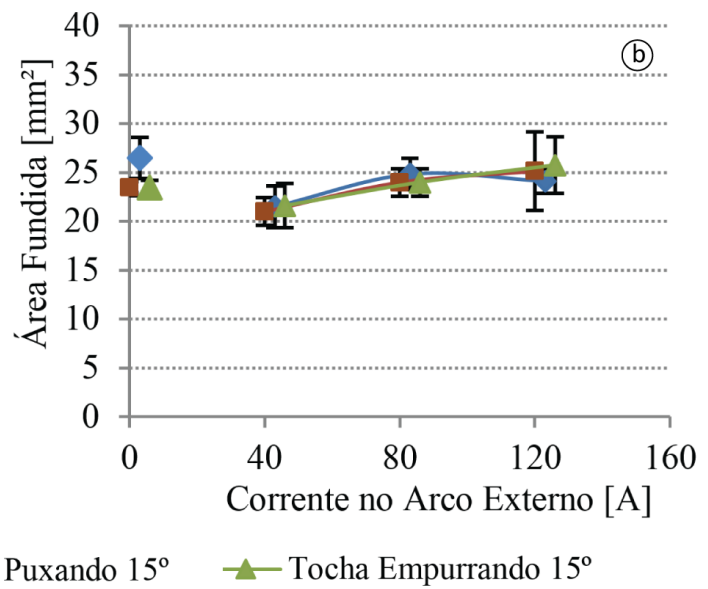

Figura 11. Penetração (a) e Área Fundida (b) do cordão de solda para o processo "Plasma-MIG" com Arcos Concêntricos em função da corrente no arco externo para três posições de Inclinação da tocha, DTP de $10 \mathrm{~mm}$ e corrente no arco interno de $250 \mathrm{~A}$ (alguns pontos foram levemente deslocados na horizontal para permitir a visualização das barras de erro). 

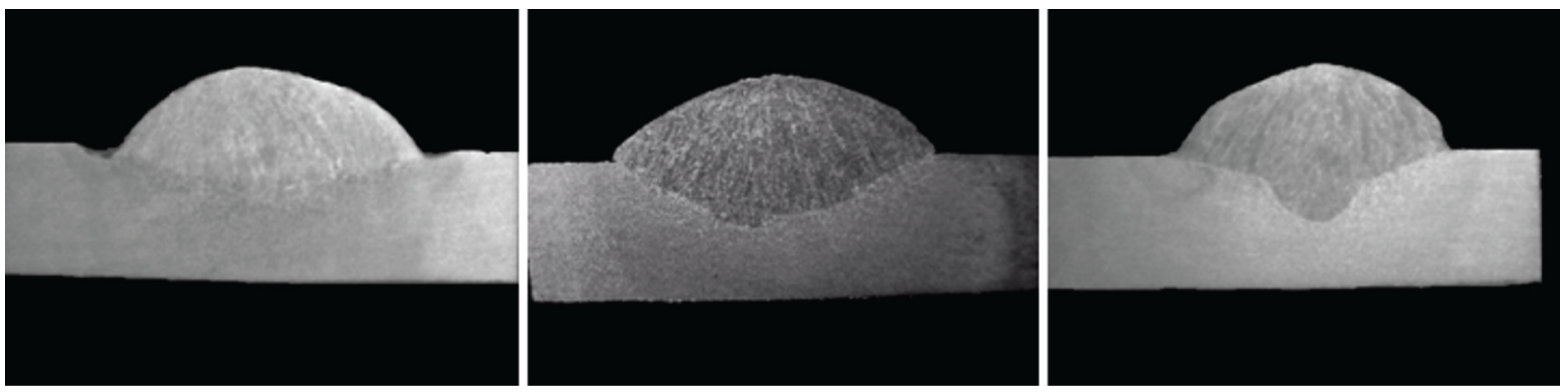

Figura 12. Seções transversais para soldagem com 250 A de corrente no arame e 40 A no arco externo para as condições empurrando (esquerda), tocha perpendicular (centro) e puxando (direita).

\section{Conclusões}

Lembrando-se de que, independente dos parâmetros, a taxa de deposição por unidade de comprimento da solda foi a mesma, conclui-se que, independentemente dos valores de corrente no arco interno, distância entre a tocha e a peça e ângulo de inclinação da tocha para o processo "Plasma-MIG" com arcos concêntricos, maiores valores de corrente externa garantem maiores taxas de deposição e, consequentemente, maiores velocidades de soldagem, produzindo cordões com maiores larguras, menores reforços, maiores penetrações e maiores áreas fundidas. Entretanto, um baixo valor de corrente externa, apesar de ainda assim aumentar a taxa de fusão do arame (permitindo maiores velocidades de soldagem para a mesma se obter um mesmo volume de cordão) não apresenta o mesmo efeito quando comparado com o processo sem corrente no arco externo, chegando a reduzir a penetração e área fundida. Desta forma, o uso da corrente externa deve ser feito pensando na aplicação, ou seja, um valor baixo em operações que exijam uma menor diluição, como por exemplo, em revestimentos, e valores altos quando penetração é importante.

Conclui-se também que outros parâmetros influem sobre a geometria do cordão, como a corrente no arco interno, a distância entre a tocha e a peça e o ângulo de inclinação da tocha. Cordões menos convexos (maiores larguras e menores reforços) são obtidos com maiores correntes no arco interno, menor distância da tocha até a peça (não é recomendado utilizar valores abaixo de $10 \mathrm{~mm}$ ) e a tocha na condição empurrando. Maiores penetrações são obtidas para maiores correntes no arco interno, menor distância da tocha à peça e tocha, mas com a tocha na posição puxando (apesar da inclinação da tocha não promover mudança na área fundida em função da mudança do perfil do cordão de solda).

\section{Agradecimentos}

Os autores agradecem ao Laprosolda/UFU pela oportunidade de utilização dos equipamentos e do suporte técnico disponibilizado. Os autores estendem ainda os agradecimentos à empresa TBi por facilitar o fornecimento da tocha utilizada nos experimentos e discussão sobre o uso da mesma. Finalmente, agradecemos aos órgãos de fomento FAPEG, Fapemig e CNPq pelo suporte financeiro para a realização dos experimentos.

\section{Referências}

[1] Oliveira MA. Desenvolvimento do processo de soldagem híbrido plasma-MIG para operações de soldagem e brasagem [tese de doutorado]. Florianópolis: Universidade Federal de Santa Catarina; 2006.

[2] Resende AA. Uma contribuição à análise dos parâmetros de soldagem do processo plasma-MIG com eletrodos concêntricos [dissertação de mestrado]. Uberlândia: Universidade Federal de Uberlândia; 2009.

[3] Harris ID. Plasma-MIG welding. In: Olson DL, Siewert TA, Liu S, Edwards GR. ASM metals handbook volume 6 - welding, brazing, and soldering. Materials Park: ASM International; 1994.

[4] Essers WG, Willems GAM, Buelens JJC, van Gompel MRM.

[5] Essers WG. New process combines plasma with GMA welding. Welding Journal. 1976;55(5):394-400.

[6] Liu Z, Ono K, Ueyama T, Era T, Tanaka M. Development of Plasma GMA Welding System. Quarterly Journal of the Japan Welding Society. 2009;27(2):45-49. http://dx.doi.org/10.2207/ qjjws.27.45s.

[7] Essers WG, Walter R. Heat transfer and penetration mechanisms with GMA and plasma-GMA welding. Welding Journal. 1981;60(3):37-42. 